\title{
Fator do plasma seminal associado à integridade de membrana de espermatozóides suínos pós-descongelamento
}

[Seminal plasma factor associated to post-thawing swine sperm membrane integrity]

\author{
I. Bianchi ${ }^{1}$, T. Collares ${ }^{1}$, V.F. Campos ${ }^{1}$, P.V. Cavalcanti ${ }^{1}$, C. Kaefer ${ }^{1}$, E.K. Corrêa ${ }^{1}$, \\ O.A. Dellagostin ${ }^{1,}$, T. Lucia Jr. ${ }^{1}$, J.C. Deschamps ${ }^{1}$, M.N. Corrêa ${ }^{1,2} *$ \\ ${ }^{1}$ Centro de Biotecnologia - UFPel - Pelotas, RS \\ ${ }^{2}$ Faculdade de Veterinária - UFPel \\ Campus Universitário $\mathrm{s} / \mathrm{n}^{\circ}$ \\ 96010-900 - Pelotas, RS
}

\begin{abstract}
RESUMO
Neste estudo, identificaram-se polipeptídeos associados à integridade da membrana plasmática (IMP) de espermatozóides suínos após o processo de congelamento/descongelamento. Por meio do perfil protéico do plasma seminal em SDS-PAGE, observou-se a presença de nove bandas polipeptídicas com pesos moleculares que variaram de 11,97 a $122,52 \mathrm{kDa}$. Detectou-se que uma banda de $26,58 \mathrm{kDa}$ esteve associada à baixa IMP ( $<55 \%)$. Não foi verificada associação entre as outras bandas e a IMP. Conclui-se que o fator polipeptídico de $26,58 \mathrm{kDa}$ está associado à baixa integridade da membrana plasmática do espermatozóide suíno após o congelamento/descongelamento.
\end{abstract}

Palavras-chave: suíno, sêmen, proteína, criopreservação, marcador bioquímico

\begin{abstract}
Polypeptides associate to membrane integrity (MI) of swine spermatozoa submitted to freezing and thawing were identified. The protein profile of seminal plasma analyzed by SDS-PAGE allowed the identification of nine polypeptide bands with molecular weight ranging from 11.97 to $122.52 \mathrm{kDa}$. One $26.58 \mathrm{kDa}$ band was associated with reduced MI (<55\%). No associations among other bands and MI were observed. The $26.58 \mathrm{kDa}$ factor is associated with reduction of membrane integrity of swine spermatozoa after freezing and thawing.
\end{abstract}

Keywords: swine, semen, protein, cryopreservation, biochemical marker

\section{INTRODUÇÃO}

O plasma seminal é um fluido com papel essencial para funções espermáticas in vivo, desde a ejaculação, até a fertilização (Kraus et al., 2005). O plasma seminal contém diferentes componentes, tais como: proteínas que são os constituintes orgânicos do fluido seminal, encontrados em maior quantidade. Essas proteínas são importantes fisiologicamente para o sêmen e estão presentes na forma de complexos associados. A composição, a conformação e o tamanho dessas proteínas são específicos para cada espécie e elas são estáveis, dependendo das condições do sêmen (Jelínková et al., 2003).

O evento da fertilização nos mamíferos inclui interações bioquímicas altamente reguladas, tais como: ligação de proteínas seminais na superfície dos espermatozóides durante a ejaculação, interação de proteínas de membrana dos espermatozóides com células epiteliais do oviduto, capacitação espermática, reconhecimento dos gametas, ligação entre os gametas, reação acrossômica, penetração do

Recebido em 2 de agosto de 2007

Aceito em 12 de março de 2008

*Autor para correspondência (corresponding author)

E-mail: marcio.nunescorrea@pesquisador.cnpq.br 
espermatozóide na zona pelúcida e fusão dos gametas (Jansen et al., 2001; Suarez et al., 2001; Strzezek et al., 2005). A membrana plasmática do espermatozóide pode sofrer remodelações quando o espermatozóide interage com proteínas do plasma seminal durante a ejaculação. Dois tipos de interações protéicas podem estar envolvidos nesse processo: a interação de proteínas com a membrana espermática e interações mútuas entre proteínas de formas monoméricas (Manásková et al., 2003).

Outras funções e características dos espermatozóides que podem ser influenciadas por proteínas do plasma seminal incluem a capacitação e a reação acrossômica (Manjunath e Thérien, 2002), bem como a motilidade espermática (Curi et al., 2003), e a integridade genômica (Chen et al., 2002). Por isso, a caracterização de proteínas presentes no plasma seminal de diferentes espécies, pela identificação dos polipetídeos, pode fornecer elementos para a certificação da fertilidade e da congelabilidade do sêmen (Killian et al., 1993; Roncoletta et al., 1999; Jobim et al., 2004; Moura et al., 2006).

Proteínas do plasma seminal bovino (BSP) foram identificadas como tendo a propriedade de ligação à superfície do espermatozóide, diminuindo sua quantidade após a criopreservação do sêmen, sugerindo alguma relação com a congelabilidade do sêmen (Nauc e Manjunath, 2000). Entretanto, é desconhecida a influência destas proteínas sobre o processo de criopreservação do sêmen. Por outro lado, a presença de um fator polipeptídico de $61,8 \mathrm{kDa}$ no plasma seminal de touros da raça GIR foi identificado como associado à congelabilidade do sêmen desta raça (Roncoletta et al., 1999). Contudo, não foram estudados polipeptídeos relacionando proteínas do plasma seminal com a integridade da membrana plasmática de sêmen suíno criopreservado.

Este trabalho teve por objetivo identificar polipeptídeos provavelmente associados à integridade da membrana plasmática do sêmen suíno submetido ao congelamento e ao descongelamento.

\section{MATERIAL E MÉTODOS}

Foram utilizados neste estudo três machos suínos adultos mantidos sob as mesmas condições ambientais e de manejo. Para a coleta, processamento e criopreservação do sêmen, foram realizadas seis coletas de cada macho. As coletas foram realizadas por meio da técnica da mão-enluvada usando-se um copo plástico protegido por um copo isotérmico recoberto por gaze, a fim de separar a fração do ejaculado rico em gel. Somente a porção do ejaculado com maior concentração espermática foi utilizada para o processo de congelamento (Westendorf et al., 1975; Bordignon et al., 1996).

Imediatamente após a coleta do sêmen, para cada macho foi obtida, da fração rica em espermatozóides, uma alíquota de $20 \mathrm{ml}$ em tubo cônico de $50 \mathrm{ml}$ e diluída $(1: 1, \mathrm{v} / \mathrm{v})$ no diluente Beltsville Thawing Solution (BTS) (Pursel e Johnson, 1975). Após a diluição inicial, foi feito o resfriamento por $90 \mathrm{~min}$ a $24^{\circ} \mathrm{C}$, e seguiu-se o resfriamento por mais $90 \mathrm{~min}$ até $15^{\circ} \mathrm{C}$, quando então foi feita a centrifugação ${ }^{1}$ a $800 x$ g por $10 \mathrm{~min}$. O sobrenadante foi descartado, e o pelete de espermatozóides foi re-suspenso no diluidor de resfriamento $(80 \%, \mathrm{v} / \mathrm{v}$, de solução de lactose a $11 \% ; 20 \%$, v/v, gema de ovo) para uma concentração de $1,5 \times 10^{9}$ espermatozóides $/ \mathrm{ml}$. O resfriamento foi realizado durante $90 \mathrm{~min}$ até $5^{\circ} \mathrm{C}$. No processo de congelamento, foi utilizada a N,N-Dimetilacetamida (DMA) $\left(\mathrm{C}_{4} \mathrm{H}_{9} \mathrm{NO}\right) \mathrm{com}$ peso molecular de 87,12 como crioprotetor intracelular. $\mathrm{O}$ diluidor de congelamento a ser adicionado a $5^{\circ} \mathrm{C}$ foi elaborado a partir do diluidor de resfriamento, acrescido de 1,5\% do detergente Orvus Ex Paste, e o respectivo crioprotetor para concentração final de $5 \%$, v $/ \mathrm{v}$, (DMA 5\%). O envase do sêmen foi feito em palhetas de $0,5 \mathrm{ml}$, com concentração final de $500 \times 10^{6}$ espermatozóides/palheta. As palhetas foram congeladas horizontalmente, $5 \mathrm{~cm}$ acima do vapor de nitrogênio líquido, por $20 \mathrm{~min}$, logo após estocadas em nitrogênio líquido a $-196^{\circ} \mathrm{C}$ até o descongelamento. As palhetas foram descongeladas a $37^{\circ} \mathrm{C}$ por $20 \mathrm{~s}$, sendo resuspensas em tubo cônico contendo $10 \mathrm{ml}$ de BTS previamente aquecido a $37^{\circ} \mathrm{C}(1: 20, \mathrm{v} / \mathrm{v})$.

Uma alíquota de sêmen fresco foi centrifugada (2000x g, $\left.10 \mathrm{~min}, 4^{\circ} \mathrm{C}\right) \operatorname{logo}$ após a coleta. O plasma seminal foi congelado e mantido em nitrogênio líquido. Para a análise, as amostras foram descongeladas e recentrifugadas (3000x g, 10min., $4^{\circ} \mathrm{C}$ ), para eliminar possível contaminação com

${ }^{1}$ Sorvall ${ }^{R}$ RC6 - DuPont Company - Wilmington, EUA. 
espermatozóides. O plasma seminal foi diluído três vezes em solução físiológica $(\mathrm{NaCl} \quad 0,9 \%)$. Cada amostra foi preparada para a corrida com $50 \mu \mathrm{l}$ de plasma seminal e $25 \mu 1$ de tampão de amostra (Glicerol; Tris-Hcl 0,6173M - pH 6,8; Bmercaptoetanol; SDS 10\%; azul-de-bromofenol; $\mathrm{H}_{2} \mathrm{O}$ ), após foram submetidas à fervura por $10 \mathrm{~min}$ para desnaturação protéica.

A eletroforese (SDS-PAGE) unidimensional do tipo descontínua (Laemmili, 1970) foi realizada com o sistema BIO-RAD Mini-Protean $3 \mathrm{Cell}^{\circledR 2}$. Foram usados géis concentrados a $15 \%$. As amostras foram concentradas a $50 \mathrm{~V}$ por $20 \mathrm{~min}$, e a corrida a $100 \mathrm{~V}$ por aproximadamente $2 \mathrm{~h}$. Como padrão foi utilizado o marcador de peso molecular BenchMark Protein Ladder ${ }^{\mathrm{TM}^{3}}$. Os géis foram corados a temperatura ambiente com Coomassie Brilliant Blue ${ }^{4}$ em over-night. Os géis foram analisados com o software TotalLab TL 100 v. $2006^{5}$.

Após o descongelamento, foi feita a avaliação da IMP espermática por fluorescência (Harrison e Vickers, 1990), por meio de sondas de diacetato de carboxifluoresceína (CFDA) e iodeto de propídio (IP). Após a incubação em temperatura de $22^{\circ} \mathrm{C}$ por $15 \mathrm{~min}$, foi feita a avaliação em microscópio de epifluorescência $\mathrm{BX} 51^{6}$, por meio de excitação em filtro WU sob aumento de 400x. Foram contados 200 espermatozóides, em uma mesma lâmina, e classificados conforme sua coloração em íntegros (corados em verde em toda sua extensão) ou lesados (corados em vermelho).

Após o descongelamento das palhetas, foi feita a distribuição de freqüências dos resultados de IMP dos espermatozóides e feita a categorização em menor de $55 \%$ e igual ou maior que $55 \%$. Com isso relacionou-se a integridade no descongelamento à presença ou ausência de cada banda protéica no plasma seminal.

\section{RESULTADOS E DISCUSSÃO}

No total, foram detectadas nove bandas protéicas no perfil eletroforético do plasma seminal (Tab. 1). O peso molecular das bandas variou de 11,97 a

${ }^{2}$ Bio-Rad Laboratories - Hercules, EUA.

${ }^{3}$ Invitrogen ${ }^{\circledR}$ - Carlsbad, EUA.

${ }^{4}$ Sigma Chemical CO. - St. Louis, EUA.

${ }^{5}$ Nonlinear Dynamics - Newcastle, Inglaterra.

${ }^{6}$ Olympus - Tokyo, Japão.
$122,52 \mathrm{kDa}$. Foram observadas diferenças no padrão do perfil eletroforético entre as amostras analisadas. Muitas proteínas com peso molecular semelhante ao das bandas detectadas foram identificadas nos bancos de dados in silico. Uma banda de $26,58 \mathrm{kDa}$ (Fig. 1) apresentou associação com a IMP. Foi observado que em $88 \%$ das amostras que apresentavam IMP $\geq 55 \%$ a banda de $26,58 \mathrm{kDa}$ estava ausente (Tab. 2). Não foi observada a associação entre outras bandas detectadas e a integridade de membrana. $O$ plasma seminal contém fatores protéicos específicos que provocam importantes efeitos tanto na capacidade de fertilização do espermatozóide quanto na fisiologia reprodutiva da fêmea (Strzezek et al., 2005). Entretanto, os efeitos biológicos específicos das proteínas do plasma seminal nas funções espermáticas são complexos e não compreendidos totalmente. Nos bancos de dados in silico foi encontrado um grupo protéico com peso molecular de aproximadamente $26 \mathrm{kDa}$ chamado Sialoproteínas, que tem por função a inibição da aglutinação das cabeças dos espermatozóides. A deficiência desse grupo pode comprometer o potencial espermático de fertilização (Strzezek et al., 2002). Usando eletroforese bidimensional (2DPAGE), Flowers (2001) demonstrou a importância biológica de duas proteínas $(26 \mathrm{kDa}, \mathrm{pI} 6,2 ; 55 \mathrm{kDa}$, pI4,8) presentes no plasma seminal de suínos, relacionadas com altas taxas de parição (em torno de $86 \%$ ). Killian et al. (1993) associaram quatro proteínas do plasma seminal com a fertilidade de touros. Duas proteínas $(26 \mathrm{kDa}, \mathrm{pI} 6,2 ; 55 \mathrm{kDa}$, pI4,5) foram detectadas em touros de alta fertilidade e outras duas $(16 \mathrm{kDa}, \mathrm{pI} 4,1 ; 16 \mathrm{kDa}$, pI6,7) estavam presentes em touros de baixa fertilidade.

Tabela 1. Peso molecular de acordo com as bandas protéicas detectadas no plasma seminal de suínos

\begin{tabular}{llll}
\hline \multirow{2}{*}{$\begin{array}{l}\text { Bandas } \\
\text { protéicas }\end{array}$} & \multicolumn{3}{l}{ Peso molecular $(\mathrm{kDa})$} \\
\cline { 2 - 4 } & Média & \pm & $\mathrm{DP}$ \\
\hline 1 & 122,52 & \pm & 2,51 \\
2 & 96,58 & \pm & 2,31 \\
3 & 85,19 & \pm & 2,9 \\
4 & 63,85 & \pm & 1,2 \\
5 & 43,62 & \pm & 2,07 \\
6 & 26,58 & \pm & 0,67 \\
7 & 17,84 & \pm & 0,6 \\
8 & 14,33 & \pm & 0,23 \\
9 & 11,97 & \pm & 0,13 \\
\hline DP= desvio-padrão & &
\end{tabular}




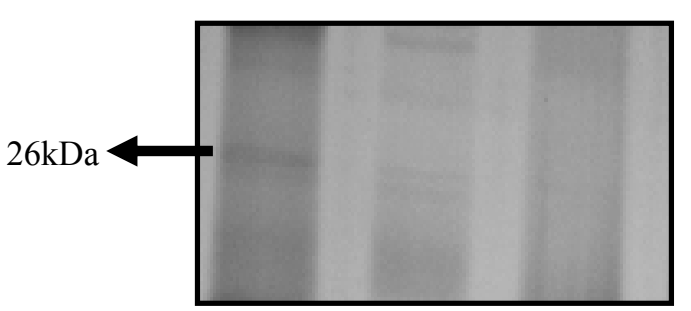

Figura 1. Banda de 26,58kDa em plasma seminal suíno

A maioria das características da superfície dos espermatozóides é adquirida no epidídimo (processo de maturação) e na ejaculação pela adsorção de componentes específicos do plasma seminal (Amann et al., 1993). É geralmente aceito que a ligação de algumas proteínas do plasma seminal estabiliza componentes da membrana plasmática, mascara antígenos expostos na superfície celular e previne contra a reação acrossômica prematura (Strzezek et al., 2005). É bem conhecido que a adsorção de elementos pela superfície celular é um processo dependente da temperatura. No caso de células espermáticas, a adsorção pode ser afetada por temperaturas de congelamento de forma que a adsorção de proteínas no sêmen congelado pode ser diferente daquele mantido à temperatura ambiente (Leeuw et al., 1990). No presente estudo, os espermatozóides foram separados do plasma seminal e congelados, o que não impede a possível influência desse fluido sobre as células espermáticas durante $\mathrm{o}$ período de processamento.

Tabela 2. Presença (Sim) e ausência (Não) de proteínas no plasma seminal de suínos relacionado com integridade de membrana plasmática $>55 \%$ descongelado

\begin{tabular}{|c|c|c|c|c|c|c|c|c|c|c|}
\hline \multirow{2}{*}{ Macho } & \multirow{2}{*}{ Perfil } & \multicolumn{9}{|c|}{ Banda, kDa, n (\%) } \\
\hline & & 122,52 & 96,58 & 85,19 & 63,85 & 43,62 & 26,58 & 17,84 & 14,33 & 11,97 \\
\hline 1 & Sim & $5(83)$ & $6(100)$ & $6(100)$ & $6(100)$ & $6(100)$ & $2(33)$ & $3(50)$ & $6(100)$ & $6(100)$ \\
\hline 1 & Não & $1(17)$ & $0(0.0)$ & $0(0.0)$ & $0(0.0)$ & $0(0.0)$ & $4(67)$ & $3(50)$ & $0(0.0)$ & $0(0.0)$ \\
\hline 2 & Sim & $3(60)$ & $3(60)$ & $5(100)$ & $5(100)$ & $2(40)$ & $0(0.0)$ & $3(60)$ & $5(100)$ & $5(100)$ \\
\hline 2 & Não & $2(40)$ & $2(40)$ & $0(0.0)$ & $0(0.0)$ & $3(60)$ & $5(100)$ & $2(40)$ & $0(0.0)$ & $0(0.0)$ \\
\hline 11 & Sim & $3(60)$ & $3(60)$ & $5(100)$ & $5(100)$ & $3(60)$ & $0(100)$ & $4(80)$ & $5(100)$ & $5(100)$ \\
\hline 11 & Não & $2(40)$ & $2(40)$ & $0(0.0)$ & $0(0.0)$ & $2(40)$ & $5(100)$ & $2(40)$ & $0(0.0)$ & $0(0.0)$ \\
\hline Total & Sim & $11(69)$ & $12(75)$ & $16(100)$ & $16(100)$ & $11(69)$ & $2(12)$ & $10(62)$ & $16(100)$ & $16(100)$ \\
\hline Total & Não & $5(31)$ & $4(25)$ & $0(0.0)$ & $0(0.0)$ & $5(31)$ & $14(88)$ & $6(38)$ & $0(0.0)$ & $0(0.0)$ \\
\hline
\end{tabular}

Em estudos realizados com suínos miniatura, observou-se que o plasma seminal contém fatores que modificam a célula espermática antes do congelamento e reduzem a capacidade de penetração no oócito após o congelamento (Kawano et al., 2004). Evidências têm demonstrando o papel de proteínas do plasma seminal na tecnologia de preservação do sêmen suíno (Ceremades et al., 2004). Portanto, o achado deste estudo poderá favorecer experimentos com sêmen suíno resfriado, em especial a $5^{\circ} \mathrm{C}$ em que a susceptibilidade ao estresse térmico é maior. Em concordância com este estudo, Jobim et al. (2004) demonstraram que há diferenças nas proteínas do plasma seminal de touros com boa e má resposta ao congelamento, sugerindo o estudo dessas proteínas do plasma como marcadores de congelabilidade. $\mathrm{O}$ uso de marcadores bioquímicos para a identificação de propriedades biológicas do sêmen poderá ajudar a desenvolver novos critérios que são precisos e objetivos na predição e melhoramento da fertilidade de machos (Fraser et al., 2006).

\section{CONCLUSÃO}

O fator polipeptídico de $26,58 \mathrm{kDa}$ está associado à baixa integridade da membrana plasmática do espermatozóide suíno após o congelamento/descongelamento.

\section{REFERÊNCIAS BIBLIOGRÁFICAS}

AMANN, R.P.; HAMMERSTEDT, R.H.; VEERAMACHANENI, D.N.R. The epididymis and sperm maturation - a perspective. Reprod. Fertil. Dev., v.5, p.361-381, 1993.

BORDIGNON, V.; DESCHAMPS, J.C.; SECHIN, A. et al. Efeito da trealose sobre a motilidade, acrossoma e fertilidade do sêmen congelado de suínos. Rev. Bras. Reprod. Anim., v.20, p.54-62, 1996.

CEREMADES, T.; CARAVAJA, G.; HERNANDEZ, M. et al. Freezing of boar semen is not affected by the addition of seminal plasma spermadhesins. Reprod. Dom. Anim., v.39, p.269, 2004. 
CHEN, H.; CHEUNG, M.P.L.; CHOW, P.H. et al. Protection of sperm DNA against oxidative stress in vivo by accessory sex gland secretions in male hamsters. Reproduction, v.124, p.491-499, 2002.

CURI, S.M.; ARIAGNO, J.I.; CHENLO, P.H. et al. Asthenozoospermia: analysis of a large population. Arch. Androl., v.49, p.343-349, 2003.

FLOWERS, W.L. Relationship between seminal plasma proteins and boar fertility. Raleigh, NC: Annual swine news, 2001. p.1-4.

FRASER, L.; WYSOCKI, P.; CIERESZKO, A. et al. Application of biochemical markers for identification of biological properties of animal semen. Reprod. Biol., v.6, p.5-20, 2006.

HARRISON, R.A.P.; VICKERS, S.E. Use of fluorescent probes to assess membrane integrity in mammalian spermatozoa, J. Reprod. Fertil., v.88, p.343-352, 1990.

JANSEN, S.; EKHLASI-HUNDRIESER, M.; TÖPFER-PETERSEN, E. Sperm adhesion molecules: structure and function. Cells Tissues Organs, v.168 p.82-92, 2001.

JELÍNKOVÁ, P.; MANÁSKOVÁ, P.; TICHÁ, M. et al. Proteinase inhibitors in aggregated forms of boar seminal plasma proteins. Int. J. Biol. Macromol., v.32, p.99-107, 2003.

JOBIM, M.I.M.; OBERST, E.R.; SALBEGO, C.G. et al. Two-dimensional polyacrylamide gel electrophoresis of bovine seminal plasma proteins and their relation with sêmen freezability. Theriogenology, v.61, p.253-266, 2004.

KAWANO, N.; SHIMADA, M.; TERRADA T. Motility and penetration competence of frozenthawed miniature pig spermatozoa are substantially altered by exposure to seminal plasma before freezing. Theriogenology, v.61, p.351-364, 2004.

KILLIAN, G.J.; CHAPMAN, D.A.; ROGOWSKI, L.A. Fertility-Associated proteins in Holstein bull seminal plasma. Biol. Reprod., v.49, p.1202-1207, 1993.

KRAUS, M.; TICHÁ, M.; ZELEZNÁ, B. et al. Characterization of human seminal plasma proteins homologous to boar AQN spermadhesins. $J$. Reprod. Immunol., v.65, p.33-46, 2005.

LAEMMILI, U.K. Cleavage of structural proteins during the assembly of the head bacteriophage T4. Nature, v.5, p.677-680, 1970.

LEEUW F.E.; CHEN, H.C.; COLENBRANDER, B. et al. Cold-induced ultrastructural changes in bull and boar sperm plasma membranes. Cryobiology, v.27, p.171-183, 1990.

MANÁSKOVÁ, P.; BALINOVA, P.; KRAUS, M. et al. Mutual interactions of boar seminal plasma proteins studied by immunological and chromatographic methods. Am. J. Reprod. Immunol., v.50, p.399-410, 2003.

MANJUNATH, P.; THÉRIEN, I. Role of seminal plasma phospholipidbinding proteins in sperm membrane lipid modification that occurs during capacitation. J. Reprod. Immunol., v.53, p.109-119, 2002.

MOURA, A.; CHAPMAN, D.A.; KOC, H. et al. A comprehensive proteomic analysis of the accessory sex gland fluid from mature Holstein bulls. Anim. Reprod. Sci., v.98, p.169-188, 2007.

NAUC, V.; MANJUNATH, P. Radioimmunoassay for bull seminal plasma proteins (BSP-A1/A2, BSP-A3, and BSP-30 kilodaltons), and their quantification seminal plasma and sperm. Biol. Reprod., v.63, p.1058-1066, 2000.

PURSEL, V.G.; JOHNSON. L.A. Freezing of boar spermatozoa: Fertilizing capacity with concentrated semen and a new thawing procedure. J. Anim. Sci., v.40, p.99-102, 1975.

RONCOLETTA, M.; FRANCESCHINI, P.H.; LIMA, V.F.H. et al. Perfil em SDS-PAGE das proteínas do plasma seminal e sua relação com a congelabilidade do sêmen de touros doadores da raça Gir. Braz. J. Vet. Res. Anim. Sci., v.36, p.141148, 1999.

STRZEZEK, J.; SAIZ-CIDONCHA, F.; WYSOCKI, P. et al. Seminal plasma proteins as markers of biological value of boar semen. Anim. Sci. Papers Rep., v.20, p.255-266, 2002.

STRZEZEK, J.; WYSOCKI, P.; KORDAN, W. et al. Proteomics of boar seminal plasma - current studies and possibility of their application in biotechnology of animal reproduction. Reprod. Biol., v.5, p.279-290, 2005.

SUAREZ, S.S. Carbohydrate-mediated formation of the oviductal sperm reservoir in mammals. Cells Tissues Organs, v.168, p.105-112, 2001.

WESTENDORF, P.; RICHTER, L.; TREU, H. Zur Tiefgefrierung von Ebersperma: Labor- und besamungsergebnisse mit dem hülsenberger pailletten-verfähren. Dtsch. Tierarztl. Wschr., v.82, p.261-267, 1975. 